\title{
Anti-ICOSL New Antigen Receptor Domains Inhibit T Cell Proliferation and Reduce the Development of Inflammation in the Collagen-Induced Mouse Model of Rheumatoid Arthritis
}

\author{
Ronan O'Dwyer, ${ }^{1}$ Marina Kovaleva $\left(\mathbb{D},{ }^{2}\right.$ Jiquan Zhang, ${ }^{3}$ John Steven, ${ }^{2}$ Emma Cummins, ${ }^{4}$ \\ Deborah Luxenberg, ${ }^{5}$ Alfredo Darmanin-Sheehan $\left(10,{ }^{6}\right.$ Miguel F. Carvalho $\left(10,{ }^{5}\right.$ \\ Matthew Whitters, ${ }^{5}$ Kenneth Saunders, ${ }^{7}$ and Caroline J. Barelle $\oplus^{2}$ \\ ${ }^{1}$ Immunocore, Long Wittenham, Oxfordshire OX14 4RY, UK \\ ${ }^{2}$ Elasmogen Ltd, Aberdeen AB25 2ZP, UK \\ ${ }^{3}$ Novartis Institutes for BioMedical Research (NIBR), Shanghai 201203, China \\ ${ }^{4}$ The Centre for Drug Research and Development (CDRD), Vancouver, BC, Canada V6T 1Z3 \\ ${ }^{5}$ Pfizer, Cambridge Park Drive, Cambridge, MA 02140, USA \\ ${ }^{6}$ Pfizer; Global Biotherapeutics Technologies, Dublin D22, Ireland \\ ${ }^{7}$ UCB New Medicines, B1420 Braine-l'Alleud, Belgium
}

Correspondence should be addressed to Marina Kovaleva; marina.kovaleva@elasmogen.com

Received 18 June 2018; Accepted 19 August 2018; Published 17 October 2018

Academic Editor: Ilaria Roato

Copyright ( 2018 Ronan O’Dwyer et al. This is an open access article distributed under the Creative Commons Attribution License, which permits unrestricted use, distribution, and reproduction in any medium, provided the original work is properly cited.

Lymphocyte costimulation plays a central role in immunology, inflammation, and immunotherapy. The inducible $\mathrm{T}$ cell costimulator (ICOS) is expressed on T cells following peptide: MHC engagement with CD28 costimulation. The interaction of ICOS with its sole ligand, the inducible T cell costimulatory ligand (ICOSL; also known as B7-related protein-1), triggers a number of key activities of $\mathrm{T}$ cells including differentiation and cytokine production. Suppression of $\mathrm{T}$ cell activation can be achieved by blocking this interaction and has been shown to be an effective means of ameliorating disease in models of autoimmunity. In this study, we isolated specific anti-ICOSL new antigen receptor domains from a synthetic phage display library and demonstrated their ability to block the ICOS/ICOSL interaction and inhibit T cell proliferation. Anti-mouse ICOSL domains, considered here as surrogates for the use of anti-human ICOSL domains in patient therapy, were tested for efficacy in a collagen-induced mouse model of rheumatoid arthritis where they significantly decreased the inflammation of joints and delayed and reduced overall disease progression and severity.

\section{Introduction}

Rheumatoid arthritis (RA) is a chronic, immune-mediated inflammatory joint disease affecting $0.5-1 \%$ of the global population and results in cartilage and bone damage as well as disability [1]. The root cause of this debilitating disease is unknown; however, increased understanding of the underlying pathology has resulted in the development of a number of effective drugs, typically with one of three modes of action: (i) neutralising the effects of inflammatory cytokines, (ii) $\mathrm{T}$ cell costimulation blockade, or (iii) B cell depletion. Currently approved biologic-based treatments for RA include TNF $\alpha$ antagonists. Three of the most successful are monoclonal antibodies targeting TNF $\alpha$ directly and blocking its binding to TNFRII: infliximab or remicade [2], adalimumab or Humira [3], and golimumab or Simponi [4]. Currently approved therapeutics also include an antibody $\mathrm{Fab}^{\prime}$ fragment conjugated to a polyethylene glycol (PEG) (certolizumab pegol or Cimzia) [5-7] and a fifth biologic, etanercept or Enbrel, which comprises of a fusion protein of TNFRII and the Fc region of human IgG1 [8]. Although targeting $\mathrm{TNF} \alpha$ has been validated through proven therapeutic efficacy 
(and significant commercial value), not all patients respond with $25-40 \%$ of subjects failing to reach the desired ACR20 end point (20\% improved response based on the American College of Rheumatology) during clinical trials [9-11]. These patients' outcomes, coupled with the fact that a follow-on study of patients on TNF $\alpha$ antagonist treatments showed that after 5 years only $44 \%$ were still taking their original therapy [12], are driving the current interest in alternative targets for treatment. To help those patients that exhibit poor or no response to TNF $\alpha$ blockade, there are a number of monoclonal antibodies seeking to treat or control the disease through an alternative biology (tocilizumab-a humanized anti-IL-6R IgG1; rituximab - a B cell-directed chimeric anti-CD20 IgG1; and abatacept-an anti-T cell costimulation inhibitor comprising an extracellular domain of CTLA-4 fused to IgG-Fc) [13-15]. However, despite these additional approaches, there still remains a significant proportion of patients that struggle to find a suitable, long-term therapy option.

Shark Ig novel antigen receptors (IgNAR) are naturally occurring binding proteins that play a pivotal role in the adaptive immune system of cartilaginous fish [16, 17]. Although there are structural similarities between IgNAR and mammalian antibodies and shared functional characteristics such as in vivo maturation, there is evidence to show that they are derived from a distinct evolutionary lineage [18]. Therefore, IgNAR could be considered a unique form of heavy chain-only antibody-like protein consisting of five constant domains followed by the variable domain (VNAR) which mediates antigen binding [19]. The lack of a light chain and therefore the lack of a corresponding hydrophobic VH-VL interface (seen in a conventional antibody) make VNARs small and highly soluble in water. Sequence analysis of VNARs has revealed a close relation to cell surface adhesion molecules and $\mathrm{T}$ cell receptors (TCR) further distinguishing them from classical antibodies [20-22]. Moreover, and unlike antibodies that generate a binding site composed of three regions of high sequence diversity (CDR1, CDR2, and CDR3) from both the variable heavy and light chain (6 in total), VNARs utilize four regions of diversity (CDR1, HV2, HV4, and CDR3) creating a 4-loop binding site within a single domain. The presence of additional noncanonical cysteine residues in frameworks 2 and 4 and CDR loops defines a series of related VNAR isotypes or structurally distinct families with diverse paratope topologies capable of binding more cryptic or hidden epitopes [23-25]. Together, their selectivity for target, biochemical properties, and small size (the smallest naturally occurring immunological-like binding domain in the vertebrate kingdom at $11 \mathrm{kDa}$ ) make VNARs attractive candidates for therapeutic drug and diagnostic development [26-29].

Here, we provide evidence of the therapeutic potency and potential of shark VNAR domains in collageninduced arthritis (CIA) in mice. This model reflects many of the immunological, histological, and clinical hallmarks of RA in humans including synovitis and cartilage and bone erosion [30].

To differentiate from the existing portfolio of anti-RA TNF $\alpha$-based therapeutics in the clinic, we chose to target and neutralise the activity of ICOSL. ICOSL, also known as
B7-related protein (B7RP-1), CD275, and B7 homologue (B7h), is a cell surface antigen expressed constitutively on antigen-presenting cells (APCs) such as B cells, activated monocytes, and dendritic cells and is the ligand for the B7 family member, ICOS (CD278) [31-33]. Initially, it was believed that its action was restricted to the activation phase of $\mathrm{T}$ cells and $\mathrm{T}$ cell-dependent $\mathrm{B}$ cell responses [34-36], but in more recent studies, the interaction between ICOS and ICOSL has been shown to play a role in the downstream survival and expansion of $\mathrm{T}$ cells (effector and regulatory) and in germinal centre (GC) formation [37, 38]. As well as promoting $\mathrm{T}_{\mathrm{FH}}$ development, Liu et al. have demonstrated the importance of ICOSL within the GC where it acts as a molecular linkage between $\mathrm{GC} \mathrm{T}_{\mathrm{FH}}$ and $\mathrm{B}$ cells resulting in positive selection of bone marrow plasma cell formation, thereby also confirming a role in the control of long-lived humoral immunity [39].

Importantly, the growing understanding of ICOSL biology has now been translated into its use as a viable therapeutic target. The completion of a successful phase I clinical study in SLE patients and phase II in Sjogren's syndrome patients (both conducted by Amgen Inc.) demonstrated efficacy of the human anti-ICOSL mAb, prezalumab [40, 41]. ICOSL and its importance in antibody-mediated disease have also been verified in several preclinical models of human disease including RA, SLE, and uveitis [32, 36, 42-46] as well as in other models of arthritis (proteoglycan-induced arthritis (PGIA) and glucose-6-phosphate isomerase- (G6PI) induced arthritis), exemplifying the utility of anti-ICOSL-binding domains in the treatment of this immune disorder [44, 47, 48]. We have previously isolated VNAR domains from an immunised Ginglymostoma cirratum (nurse shark) library, which block the ICOS/ICOSL interaction, and went on to demonstrate their efficacy in a mouse model of noninfectious uveitis [42]. Here, we have selected and ranked domains isolated from a synthetic VNAR library. This library is based on optimized Squalus acanthias spiny dogfish frameworks and contains significant engineered binding loop diversity. We have demonstrated the efficacy of anti-ICOSL VNARs in a model of RA, extending their potential as therapeutics for treatment of a range of autoimmune diseases.

\section{Materials and Methods}

2.1. VNAR Phage Display Library Screening. All clones were isolated from a synthetic VNAR library containing 100 billion unique clones. Solid-phase, phage display library antigen selections were carried out as detailed previously [49] using MaxiSorp immunotubes (Nunc, 444474) coated with $1-0.1 \mu \mathrm{g} / \mathrm{ml}$ antigen in PBS $\mathrm{pH}$ 7.4. Predecorated biotinylated antigen bead selection protocols were adopted from our previous work [42]. Outputs from each selection round were screened for antigen-specific binders by monoclonal phage and periplasmic extract ELISAs against human or mouse ICOSL and unrelated protein controls at $1 \mu \mathrm{g} / \mathrm{ml}$ in PBS coating concentration. Phage binders were detected using HRP-conjugated anti-M13 antibody (GE Healthcare, 27942101), and periplasmic protein was detected using 
HRP-conjugated to an anti-c-Myc antibody (Roche, 118 $14150001)$.

2.2. Expression and Purification of VNAR Fc-Fusion Proteins. Selected positive monomeric VNAR domains were PCRamplified and subcloned into a proprietary Fc-fusion mammalian expression vector. Proteins were transiently expressed in HEK 293 cells and subsequently purified by Protein ASepharose. Expression levels of VNAR-Fc fusion proteins were generally in the region of $50-60 \mathrm{mg}$ per litre using serum-free media. Postexpression cells and debris were removed from conditioned media by centrifugation and $0.2 \mu \mathrm{m}$ filtration. Following affinity chromatography, as detailed above, proteins were subjected to a final polishing step by size-exclusion chromatography (SEC) using a Superdex 200 26/60 column equilibrated with PBS. Eluted peaks from SEC were concentrated using Amicon ultrafiltration units and protein concentrations determined by UV spectroscopy. Electrophoresis of purified protein samples was performed on NuPAGE 4-12\% Bis-Tris gels using the MOPS buffer system (Invitrogen) in accordance with the manufacturer's instructions. Proteins were then visualised by silver staining (Life Sciences, SilverQuest LC6070) and purity determined prior to in vivo experimental work.

2.3. Cell-Based Binding Assays. CHO cells expressing human or murine ICOSL were grown to confluency in DMEM/F12+ $5 \%$ FBS media, in 96-well cell culture plates (Greiner, BioOne). Anti-ICOSL-VNAR-Fc $(50 \mu \mathrm{l})$ was added to the corresponding cells. Cells were incubated for $1 \mathrm{~h}$ at $16^{\circ} \mathrm{C}$, gently washed $3 \mathrm{x}$ with DMEM/F12+ $2 \% \mathrm{FBS}$, and incubated for another $40 \mathrm{~min}$ at $16^{\circ} \mathrm{C}$ with goat anti-human Fc-HRP (SIGMA) diluted 1:10000 in the same media. Cells were washed a further 3 times with DMEM/F12+ 2\% FBS media and once with PBS; lastly, TMB substrate was added and allowed to develop.

2.4. Cell-Based Ligand-Receptor Blocking Assays. CHO cells expressing murine or human ICOS receptor were used in blocking assays as described in our previous publication [42].

2.5. Murine D10 T Cell Proliferation Assays. Tosyl-activated magnetic Dynabeads were coated per product insert instruction with mICOSL, anti-mu CD3e, and hIgG1 filler ( $1 \mu \mathrm{g}$ ICOSL $/ 0.5 \mu \mathrm{g}$ anti-CD3/3.5 $\mu \mathrm{g}$ hIgG1 per $1 \times 10^{7}$ beads). Prior to assay setup, beads were titred to determine the optimal concentration to give a reading of approximately 8000 40,000 CPM. Beads ( $50 \mu \mathrm{l} /$ well) were added to a 96 -well plate containing titred antibody diluted in $100 \mu \mathrm{l}$ of RPMI, $10 \%$ FCS, $2 \mathrm{mM}$ glutamine, penicillin/streptomycin, $10 \mathrm{mM}$ HEPES, $1 \mathrm{mM} \mathrm{Na}$ pyruvate, $2 \mathrm{~g} / \mathrm{l}$ glucose, and $50 \mu \mathrm{M}$ BME. D10.G4.1 cells were washed $4 \mathrm{x}$ with assay media and resuspended in the above medium plus $10 \%$ rat $\mathrm{T}$ stimulatory factor with Con A (BD cat\#354115), $2.5 \mathrm{ng} / \mathrm{ml} \mathrm{IL}-2$, and $10 \mathrm{pg} / \mathrm{ml} \mathrm{IL-1}$ alpha to $8 \times 10^{5}$ cells $/ \mathrm{ml}$ and added at $50 \mu \mathrm{l} /$ well $=40,000$ cells/well. All wells were brought up to a final volume of $200 \mu \mathrm{l}$ and incubated for $48 \mathrm{~h} .{ }^{3} \mathrm{H}$-thymidine $(1 \mu \mathrm{Ci} /$ well) was added and incubated for $5-7 \mathrm{~h}$. Cells were then harvested and counts taken. $\mathrm{T}$ cell proliferation assays to assess anti-hICOSL VNAR domains were conducted using primary human $\mathrm{T}$ cells isolated from normal healthy donors. The method, in brief, was as follows: for the primary plate coating, $1 \mu \mathrm{g} / \mathrm{ml}$ anti-huCD3 clone OKT3 (eBioscience cat. \#16-5889aCD3) plus $10 \mu \mathrm{g} / \mathrm{ml}$ anti-hIgG (Jackson ImmunoResearch cat. \#109-006-098) in PBS in a total of $100 \mu \mathrm{l} /$ well was added to a 96-well plate and incubated overnight at $4^{\circ} \mathrm{C}$. Residual solution was removed and the plate washed twice with PBS. For the secondary coating, $4 \mu \mathrm{g} / \mathrm{ml} \mathrm{rhB} 7-2 /$ CD86-Fc (R\&D Systems cat. \#141-B2-100) plus $500 \mathrm{ng} / \mathrm{ml}$ rhB7-H2-Fc (R\&D Systems cat. \#165-B7-100) was added in PBS at $100 \mu \mathrm{l} /$ well and incubated for $3 \mathrm{~h}$ at room temperature followed by washes with PBS. Media ( $50 \mu \mathrm{l})$ were added to all wells of the assay plate in addition to $50 \mu \mathrm{l} \mathrm{CD} 4^{+} \mathrm{T}$ cells (diluted to give $2 \times 10^{6}$ cells $/ \mathrm{ml}$ ) and $50 \mu \mathrm{l}$ of test antibodies diluted to $3 \mathrm{x}$, with the desired final concentration in media giving a final cell concentration of $1 \times 10^{5}$ cells/well. The samples were incubated for 3 days then pulsed with $1 \mu \mathrm{Ci} /$ well of ${ }^{3} \mathrm{H}$-thymidine for $6-8 \mathrm{~h}$ on day 3 and counts measured.

2.6. FACS Analysis. Parental and mICOSL and hICOSL ligand-expressing $\mathrm{CHO}$ cells were washed in $\mathrm{PBS}$ and removed from flasks by the addition of PBS and 5\% EDTA at $37^{\circ} \mathrm{C}$ for $10-15 \mathrm{~min}$. Cells were monodispersed by pipetting up and down against the surface of the flask, spun down at $1200 \mathrm{rpm}$, and resuspended in DMEM plus 5\% FCS. Cells were aliquoted at a density of $0.5-1 \times 10^{6}$ cells/well into a 96well U-bottomed plate. Cells were incubated with $100 \mu \mathrm{l}$ tissue culture supernatant containing HEK293 VNAR-Fc expressed proteins for $30 \mathrm{~min}$ at $16^{\circ} \mathrm{C}$ followed by $3 \mathrm{x}$ washes with PBS plus 2\% FCS. Cells were then incubated with $100 \mu \mathrm{l}$ anti-hFc biotin (eBioscience \#13-4998) at $1 \mu \mathrm{g} / \mathrm{ml}$ for $30 \mathrm{~min}$ at $16^{\circ} \mathrm{C}$. After $3 \mathrm{x}$ washes with PBS plus $2 \% \mathrm{FCS}$, streptavidin APC (eBioscience \#17-4717) was added at $1 \mu \mathrm{g} / \mathrm{ml}$ for $30 \mathrm{~min}$ at $16^{\circ} \mathrm{C}$. After $1 \mathrm{x}$ wash with PBS plus $2 \%$ FCS, cells were resuspended in $400 \mu \mathrm{l}$ PBS plus $2 \%$ FCS and transferred into FACS tubes for analyses on a FACSCanto 2.

2.7. PK/PD Study. Test protein $(\mathrm{CC} 3-\mathrm{Fc})$ was assessed for endotoxin, viral, mycoplasma, and bacterial contamination to ensure quality standards required for animal testing were achieved. A group of six DBA1 mice were injected with $4 \mathrm{mg} / \mathrm{kg}$ of CC3-Fc either intravenously or subcutaneously. Blood samples $(0.3 \mathrm{ml})$ were collected after $1,3,6,24,48$, $120,168,336$, and 340 hours via the saphenous vein into EDTA tubes following a spin at $3000 \times \mathrm{g}, 4^{\circ} \mathrm{C}$ for $10 \mathrm{~min}$ for plasma recovery.

2.8. Plasma Pool down and LC-MS Analyses of PK Samples. CC3-Fc concentrations in plasma were analysed by quantitative LC-MC method described by Steven et al. [50]. Briefly, $50 \mu \mathrm{l}$ Protein A-Sepharose was added to wells of a Millipore filter plate and conditioned with PBS pH 7.4. Plasma samples were diluted $1: 4$ with PBS and added to the filter plate, incubated at room temperature and agitated at $700 \mathrm{rpm}$ for $1 \mathrm{~h}$. Wells were washed four times with $200 \mu \mathrm{l}$ PBS using a vacuum manifold. Bound Fc protein was eluted twice with $25 \mu \mathrm{l}$ of $100 \mathrm{nM}$ glycine $\mathrm{pH} 2.0$ into a low-bind deep-well block and neutralised by adding $7.5 \mu \mathrm{l} 2 \mathrm{M}$ Tris $\mathrm{pH}$ 8.0. Eluted protein samples were then trypsin-digested by addition of 
$20 \mu \mathrm{l}$ of proteomics-grade trypsin (made up at $20 \mu \mathrm{g} / \mathrm{mL}$ in $10 \mathrm{mM} \mathrm{CaCl}_{2}, 50 \mathrm{mM}$ Tris-HCl, $\mathrm{pH}$ 8.0) followed by incubation at $37^{\circ} \mathrm{C}$ for $18 \mathrm{~h}$ prior to LC-MS/MS analysis. Samples were analysed using LC-MS/MS by monitoring tryptic signature peptides resulting from $\mathrm{CC} 3-\mathrm{Fc}$ present in the samples.

2.9. Murine Collagen-Induced Arthritis Model. All animal work was conducted by Charles River Laboratories, Ann Arbor, Michigan. All animal studies were carried out under the Animals (Scientific Procedures) Act 1986 regulations (Home Office UK). Test proteins were assessed to ensure quality standards required for animal testing were achieved (as above). In vivo efficacy of anti-mICOSL hits were determined in a mouse model of rheumatoid arthritis (RA) based on Iwai et al. [51], where groups of 10 female DBA1 mice were injected with bovine collagen in Freund's Complete adjuvant (day 0) followed by a boost on day 20. AntimICOSL VNAR-Fc domains and positive (HK5.3 mAb) and negative controls (2V-Fc and rat CHOCK IgG2) were dosed intraperitoneal on days $19,21,23$, and 25 at $15 \mathrm{mg} /$ $\mathrm{kg}$ in PBS. Clinical scores and weight were measured twice weekly. Clinical scores were based on calliper measurements of footpad and digit inflammation: $1 \mathrm{pt} / \mathrm{digit}$, $5 \mathrm{pts} / \mathrm{swollen}$ footpad, and $5 \mathrm{pts} / \mathrm{swollen}$ ankle therefore giving a possible total of 15 pts/foot and 60 pts/animal. Histology was conducted on the back left foot of each animal where sections of $100 \mu \mathrm{m}$ steps were taken and stained with haematoxylin $\&$ eosin and scored for inflammation, pannus formation, cartilage damage, bone resorption, and periosteal change.

2.10. Statistical Analysis. Significant differences between experimental groups were analysed by the Mann-Whitney $U$ test. Values of $p=0.05$ were considered to be significant.

\section{Results}

3.1. Isolation of ICOSL-Specific VNAR Domains. ICOSL-specific domains were isolated from a synthetic VNAR library using phage display technology. Three selection rounds were sufficient to obtain panels of VNARs specific to mouse ICOSL, human ICOSL, or cross-reactive clones (Figure 1). We have previously reported the isolation of anti-mouse ICOSL binders from a Ginglymostoma cirratum-immunised library which were cross-reactive with human and mouse ICOSL. Although these binders could recognise both species forms, they could only block mouse ligand-receptor interactions and not the interaction between human ligand and its receptor [42]. In an attempt to bias the selection of VNARs from the synthetic library that showed both receptor-ligand blocking and species cross-reactivity, a cell-based blocking assay as well as a cross-reactive selection campaign were introduced at an early stage of screening, with parallel selection and screening for mouse only or human only targets also included. In addition, two different antigen presentation regimes were utilized, with biotinylated antigen immobilised on streptavidin-coated beads and direct immobilisation of antigen on immunotubes, both conducted to explore the full diversity of the library. A total of 24 unique anti-murine ICOSL VNAR clones which block the mICOS/mICOSL

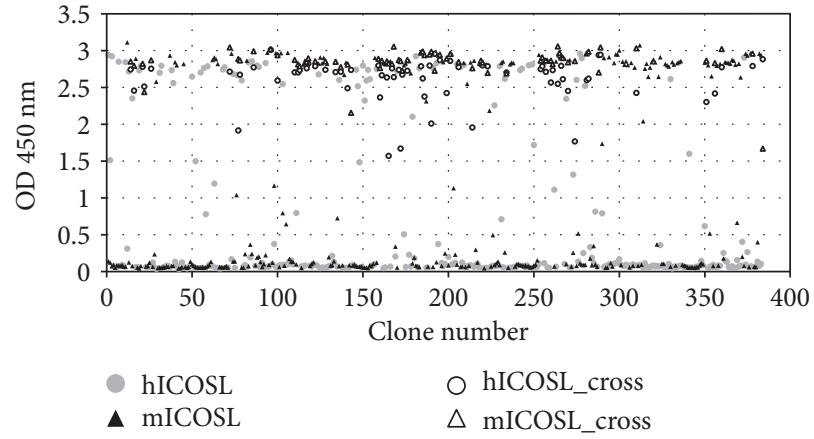

FIgURE 1: Selection of ICOSL-specific VNAR domain outputs from selection against mICOSL or hICOSL tested for binding to both ligands in ELISA. Each triangle and circle denote a clone; black fill triangles are clones binding to mICOSL only, and grey fill circles are clones binding to hICOSL only; open circles are cross-reactive clones binding to hICOSL, and open triangles are the same clones binding to mICOSL.

interaction and 12 unique anti-human ICOSL blocking the hICOS/hICOSL interaction were identified. In this instance, and despite the stringency of the selection conditions, selected cross-reactive clones were again not able to block either murine or human receptor/ligand interactions (data not shown).

To determine the efficacy of VNAR domains in an in vivo mouse model, all selected VNAR clones were converted into an Fc-fusion format to facilitate an extension of serum halflife and binding avidity. VNAR domains alone are cleared rapidly in vivo, and whilst this may be useful for some therapeutic applications, an extended half-life was expected to be required for full efficacy [17]. VNAR-Fc proteins were expressed transiently in HEK-293 cells and purified by protein A affinity chromatography followed by size exclusion chromatography. All converted clones expressed protein at levels of $50-60 \mu \mathrm{g} / \mathrm{ml}$.

3.2. VNAR Domains Assessed by In Vitro Cell-Based Binding Assays. The ability of purified anti-ICOSL VNAR-Fc domains to retain their ability to bind to cell surface expressing ICOSL ligand was confirmed by titration in cell-based ELISAs. Of the 24 anti-mICOSL VNAR-Fc proteins assessed, domains AG2, AG12, A1, CC3, and C4 were the most potent with $\mathrm{IC}_{50}$ values ranging from 0.15 to $0.35 \mathrm{nM}$. Consequently, these were selected as the lead anti-mICOSL VNARs based on both their cell binding (Figures 2(a)) and potent inhibition of the interaction between ICOSL and ICOS (Figure 2(c)). Similarly, the 12 selected anti-hICOSL clones were ranked based on binding (Figure 2(b)) and potency of neutralisation (Figure 2(d)) - of these, 2D4, 1A1, 1C8, 1H2, and $1 \mathrm{D} 12\left(\mathrm{IC}_{50}\right.$ values ranging from 0.5 to $\left.9.9 \mathrm{nM}\right)$ were selected as leads. The VNAR domain $2 \mathrm{~V}$ was included as an isotype control for all in vitro and in vivo assays. This clone, originally isolated from the dogfish Squalus acanthias, was part of a sequence analysis of naïve VNARs from this species and has no known target, making it an ideal negative control for these and other published studies [17]. 


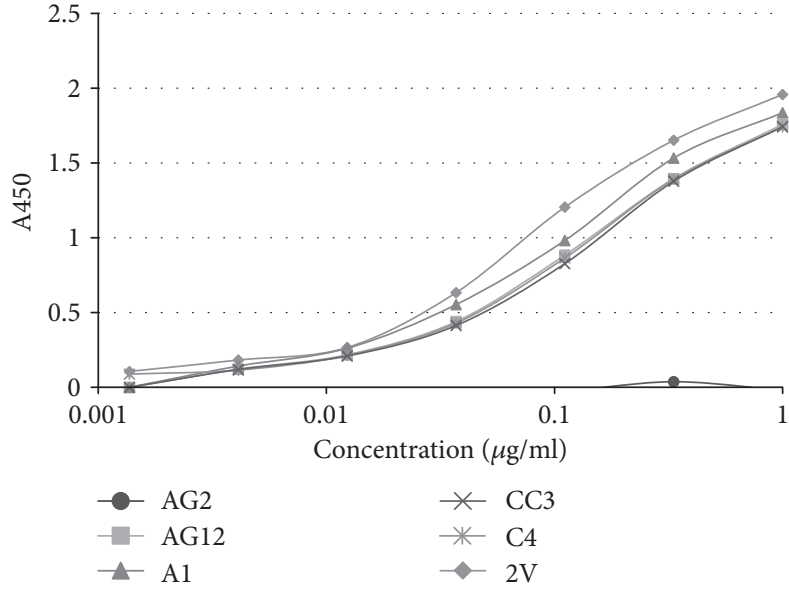

(a)

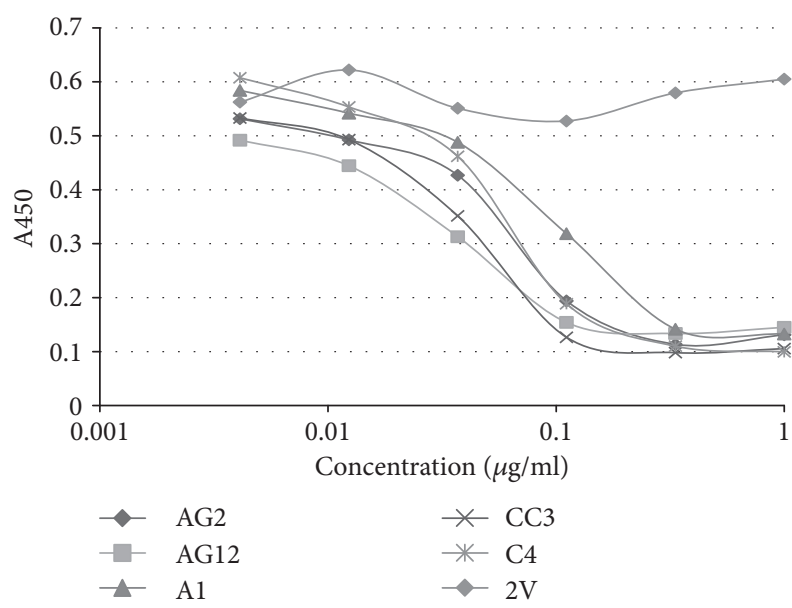

(c)

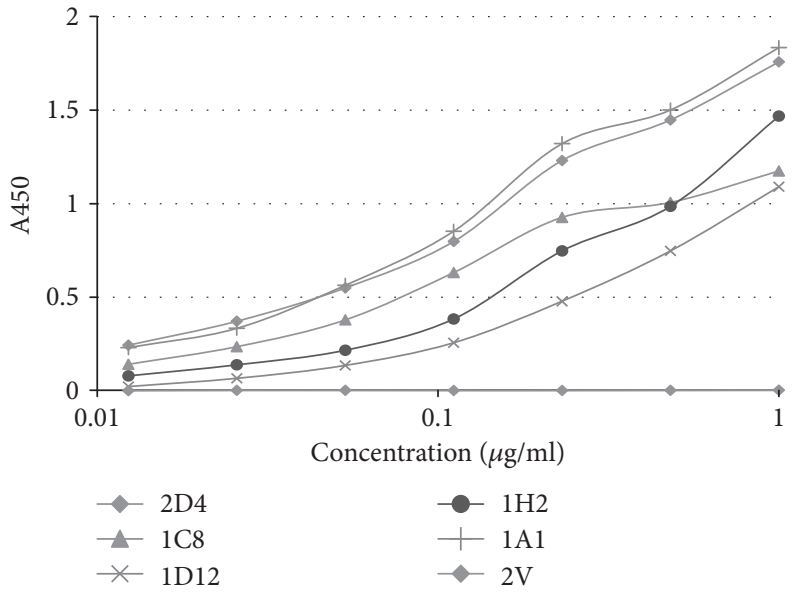

(b)

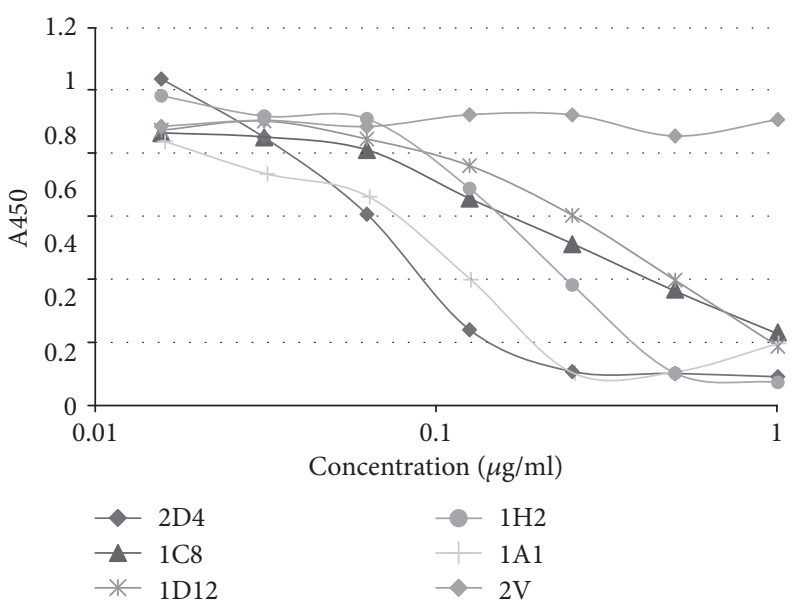

(d)

FIGURE 2: Cell-based binding and ICOS/ICOSL blocking assays. Lead anti-mICOSL and anti-hICOSL VNAR-Fc proteins were tested for binding to the CHO cell surface expressed ICOSL and their corresponding efficacy in an ICOS/ICOSL blocking assay. (a) Titration curves of anti-mICOSL VNAR-Fc domains binding to mICOSL-CHO cells. (b) Titration curves of anti-hICOSL VNAR-Fc domains binding to hICOSL-CHO cells. (c) Concentration-dependent inhibition of mICOSL-Fc binding to cell surface expressing mICOS by the addition of serial dilutions of anti-mICOSL VNAR-Fc domains. (d) Concentration-dependent inhibition of hICOSL-Fc binding to cell surface expressing hICOS by the addition of serial dilutions of anti-hICOSL VNAR-Fc domains. 2V-Fc is the VNAR isotype control in each experiment.

Cell surface target selectivity was assessed by flow cytometry analysis with $\mathrm{CHO}$ cells overexpressing human ICOSL or murine ICOSL. All of the anti-mICOSL domains showed clear binding to mICOSL-CHO cells and negligible binding to hICOSL-CHO compared to the parental CHO control, with the exception of clone $\mathrm{C} 4$ that showed a modest level of binding to hICOSL-CHO and control cells (Figure 3(a)). A similar range of specificities was seen for the antihICOSL domains. They all showed strong binding to hICOSL-CHO cells with clones $1 \mathrm{~A} 1$ and $1 \mathrm{C} 8$, also displaying weak binding to control $\mathrm{CHO}$ cells (Figure 3(b)).

\subsection{Suppression of T Cell Proliferation by Anti-ICOSL VNAR} Domains. ICOSL, on the surface of antigen-expressing cells, plays an integral role in the activation of $\mathrm{CD}^{+} \mathrm{T}$ cells through its interaction with ICOS. This cell-cell interaction results in a cascaded proliferation of helper T cells. To recreate this effect in vitro and determine whether the identified lead domains could block this downstream intracellular signalling, $\mathrm{T}$ cell assays were performed where murine or primary human $\mathrm{T}$ cells were activated by the addition of ICOSL and costimulators. All five anti-mICOSL VNAR-Fc proteins inhibited $\mathrm{T}$ cell proliferation in a dose-dependent manner compared to the $2 \mathrm{~V}$ isotype control (Figure 4(a)). Domain CC3 consistently showed the greatest efficacy with an average $\mathrm{EC}_{50}$ of $792 \mathrm{pM} \pm 143(n=11)$. The ability of the anti-hICOSL VNAR domains to inhibit T cell proliferation was determined using primary cells isolated from individual donors (Figure 4(b)). All five lead domains demonstrated picomolar $\mathrm{EC}_{50}$ values in this assay with the best clones having values of $8.5 \pm 3.6 \mathrm{pM}(1 \mathrm{~A} 1), 9 \pm 2 \mathrm{pM}$ (1C8), and 7.5 $\pm 2.1 \mathrm{pM}(2 \mathrm{D} 4)$.

3.4. Pharmacokinetics, Dynamics, and Metabolism of AntimICOSL VNAR Domain. A preliminary PK/PD study was conducted within the mouse strain matched to the intended 

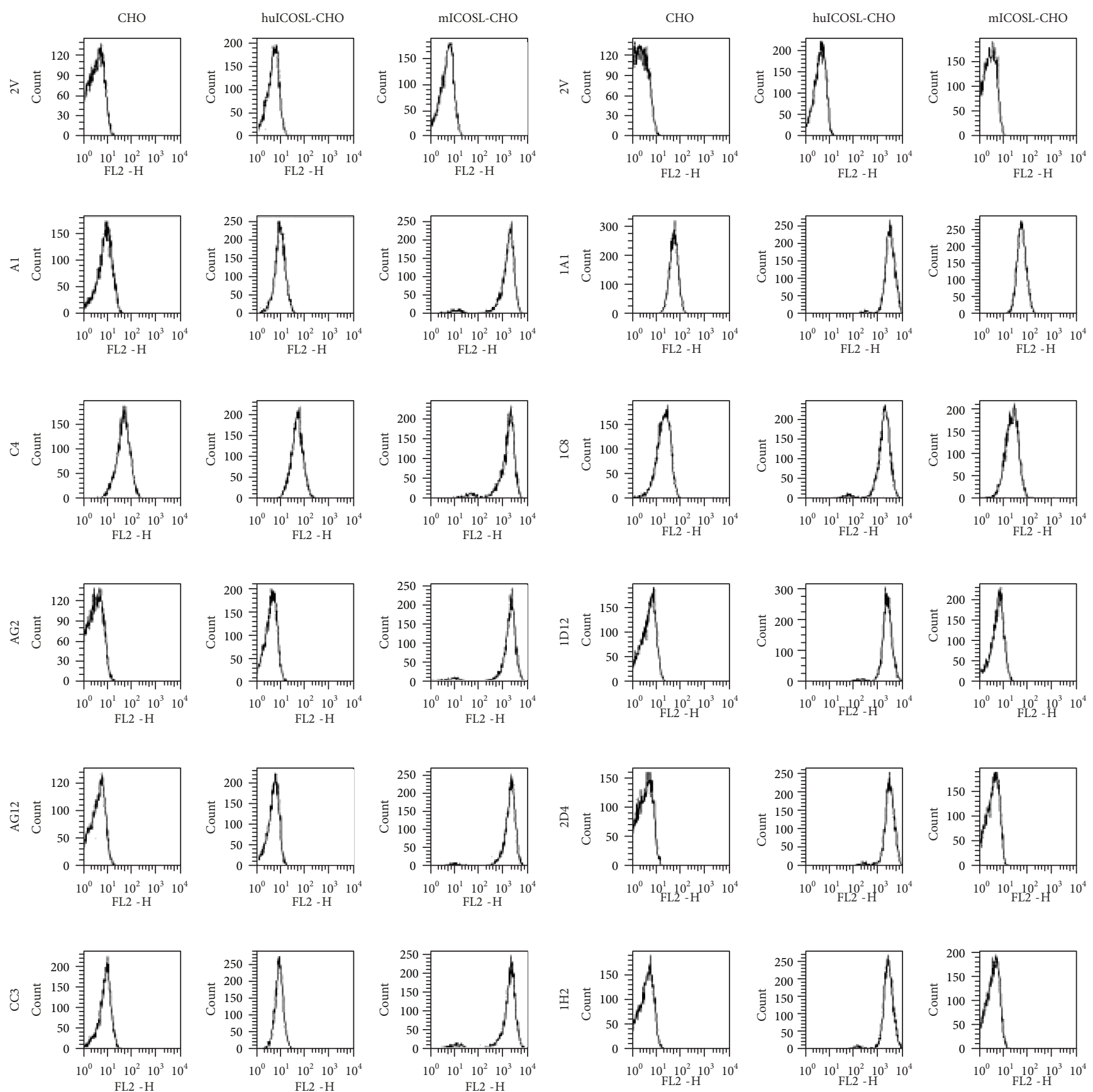

(a)
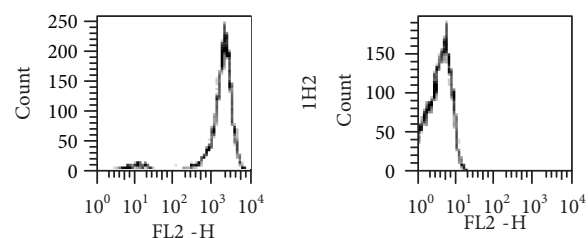
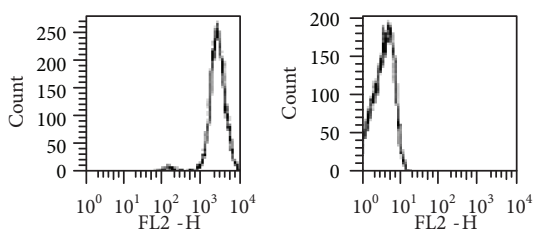

(b)

FIGURE 3: Flow cytometry analysis of lead domains binding to CHO cells. Lead anti-mICOSL and anti-hICOSL VNAR domains were tested for binding to cell surface expressing hICOSL, mICOSL, and parental CHO cells. (a) Anti-mICOSL VNAR domains were incubated with different CHO cell populations overexpressing either human or mouse ICOSL. (b) Anti-hICOSL VNAR domains were incubated with different $\mathrm{CHO}$ cell populations overexpressing either human or mouse ICOSL. To assess any nonspecific binding events, parental CHO cells were included as a cell control and 2V-Fc as a nonbinding VNAR domain control. Assays were repeated 3 times with representative data shown.

arthritis model, DBA1, with a single dose at $4 \mathrm{mg} / \mathrm{kg}$ of CC3Fc administrated either intravenously (i.v.) or subcutaneously (s.c.). The Fc part of the CC3-Fc molecule was utilized for sample enrichment using the Protein A-Sepharose capture step, and protein concentrations were determined in plasma samples. A quantitative LC-MS/MS method previously described by Steven et al. [50] was used for analysis and PK assessment. The PK profiles are shown in Figure 5 and the pharmacodynamic parameters summarised in Table 1.

\subsection{Evaluation of Anti-mICOSL VNAR Domains in a Murine} Model of Collagen-Induced Arthritis (CIA). Protein homology between mouse and human ICOSL is approximately 


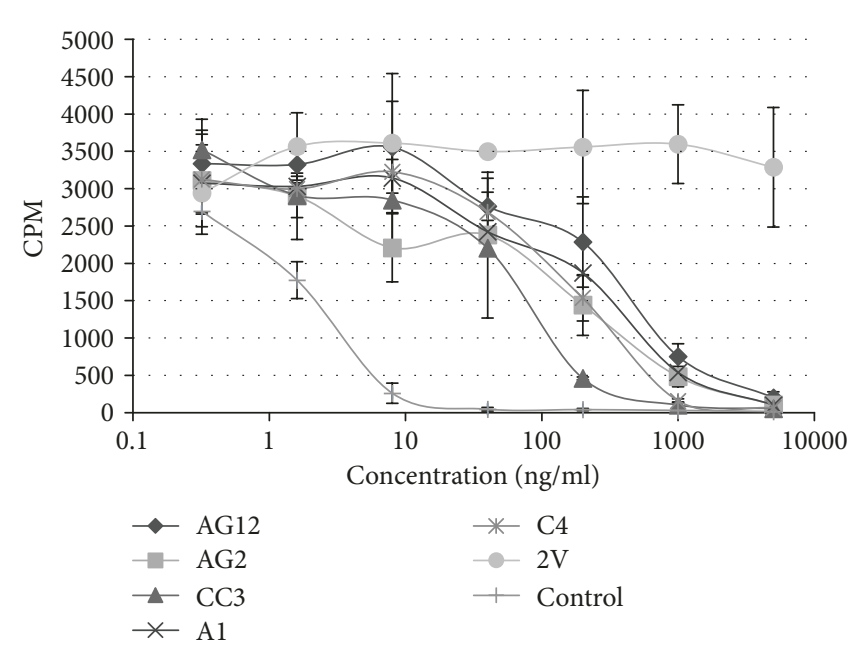

(a)

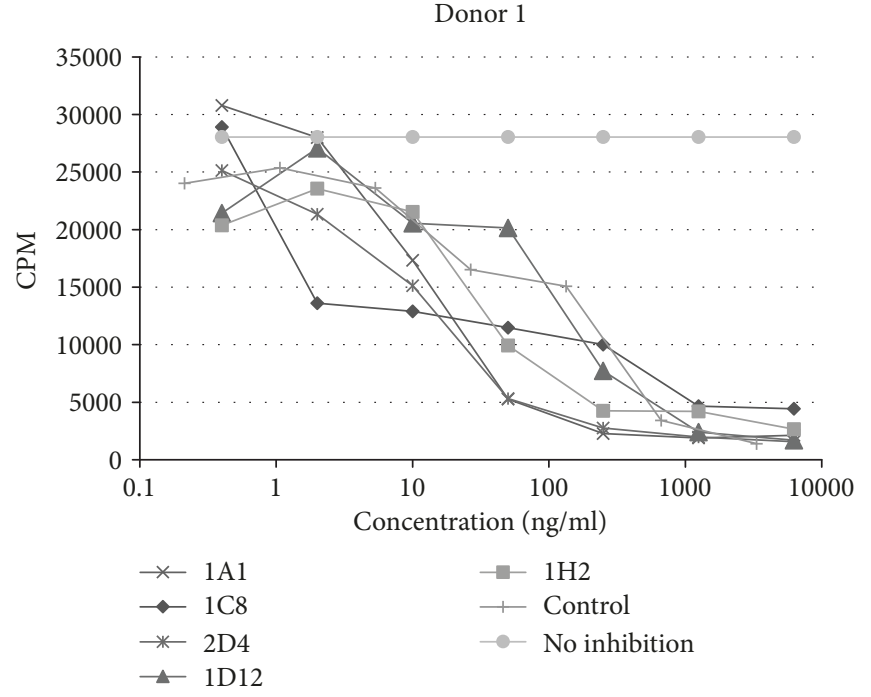

(b)

Donor 2

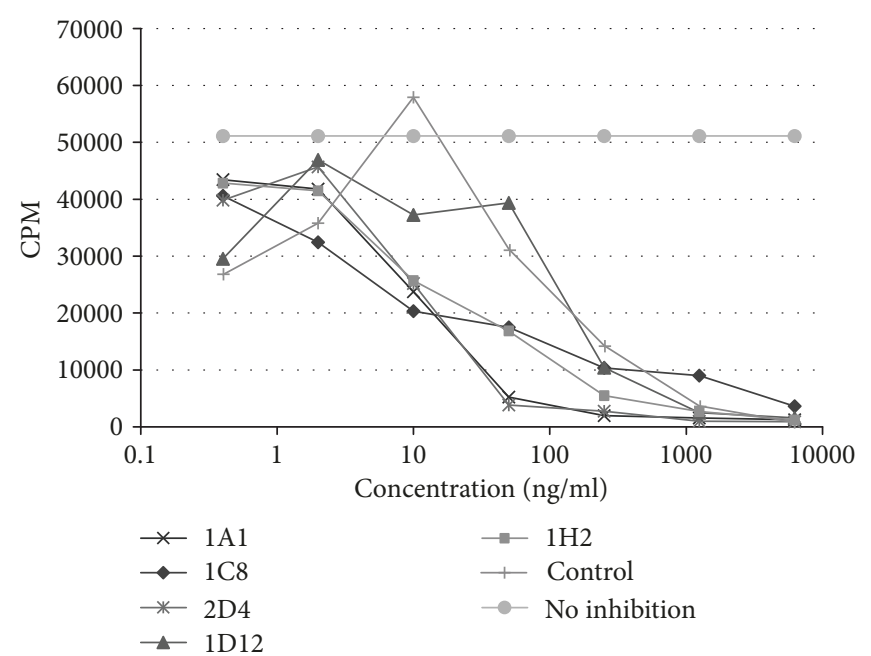

(c)

Figure 4: $\mathrm{T}$ cell proliferation assays mouse $\mathrm{T}$ cell line (a) and human primary $\mathrm{T}$ cell ( $\mathrm{b}$ and $\mathrm{c}$ ) proliferation assays were conducted to determine the efficacy of anti-mICOSL and anti-hICOSL VNAR-Fc proteins to block ICOS-ICOSL-induced cell proliferation, respectively. (a) Concentration-dependent inhibition of proliferation by lead anti-mICOSL VNAR-Fc proteins $(n=3)$. $2 \mathrm{~V}$-Fc was included in each experiment as the VNAR isotype control. (b, c) Efficacy of lead anti-hICOSL VNAR-Fc domains in two independent primary human T cell proliferation assays from two different donors. The positive controls in each experiment were in-house developed anti-human and mouse ICOSL monoclonal antibodies. Assays were repeated 3 times with representative data shown.

$43 \%$; therefore, only the anti-mouse domains could be tested in this surrogate RA model. The CIA model was carried out by Charles River Laboratories, Ann Arbor, Michigan as follows. DBA/1J mice were immunised with bovine collagen in Freund's complete adjuvant (day 0 ) and then boosted with a second administration of collagen on day 21. Fc-fusion versions of anti-mICOSL VNAR, together with the isotype format control $2 \mathrm{~V}$, were administered intraperitoneally (i.p.) at $15 \mathrm{mg} / \mathrm{kg}$ on days $19,21,23$, and 25 , except for clone C4 which was administrated at a concentration of $8.4 \mathrm{mg} / \mathrm{kg}$. Clinical scores were measured twice weekly as described in the Materials and Methods. The average clinical score was measured in each experimental group (10 animals) over the 50-day time period of the study with a score of 60 representing the maximum level of inflammation (Figures 6(a) and 6(b)). Administration of A1 and CC3 VNAR-Fc proteins resulted in a significant decrease $(p<0.05)$ in overall clinical score and a clear lag in the onset of any disease compared to the relevant isotype control. The anti-murine ICOSL monoclonal IgG HK5.3 was used as the positive biologic control [51]. The calliper measurements of footpad and digit inflammation (clinical score) were similar for $\mathrm{A} 1, \mathrm{CC} 3$, and the positive control (HK5.3) groups. The reduction in inflammation translated into visible histopathology differences at the tissue level in the left hind limb of each animal. Animals treated with dexamethasone, 


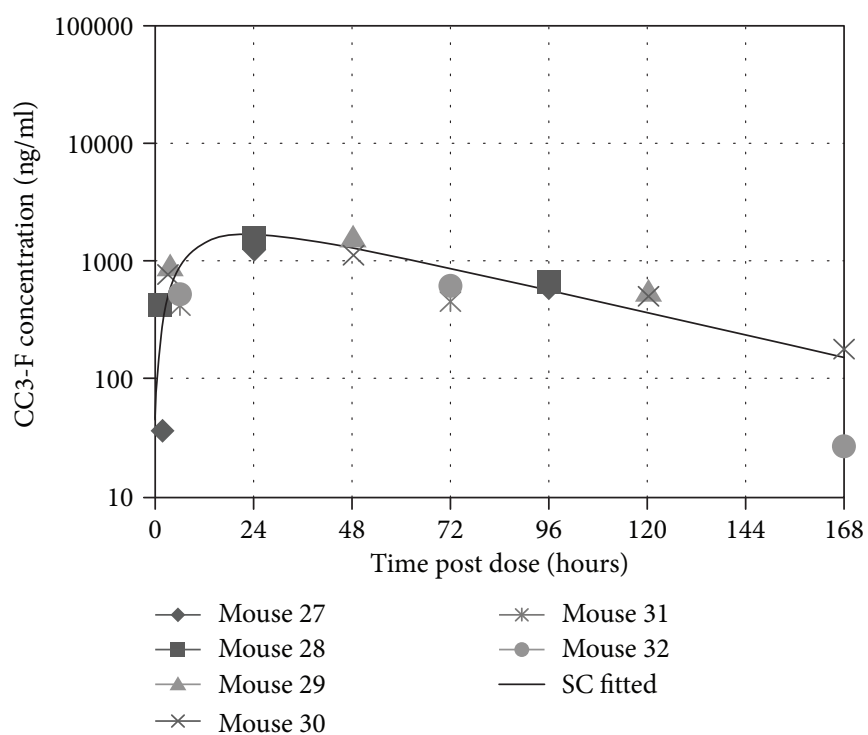

(a)

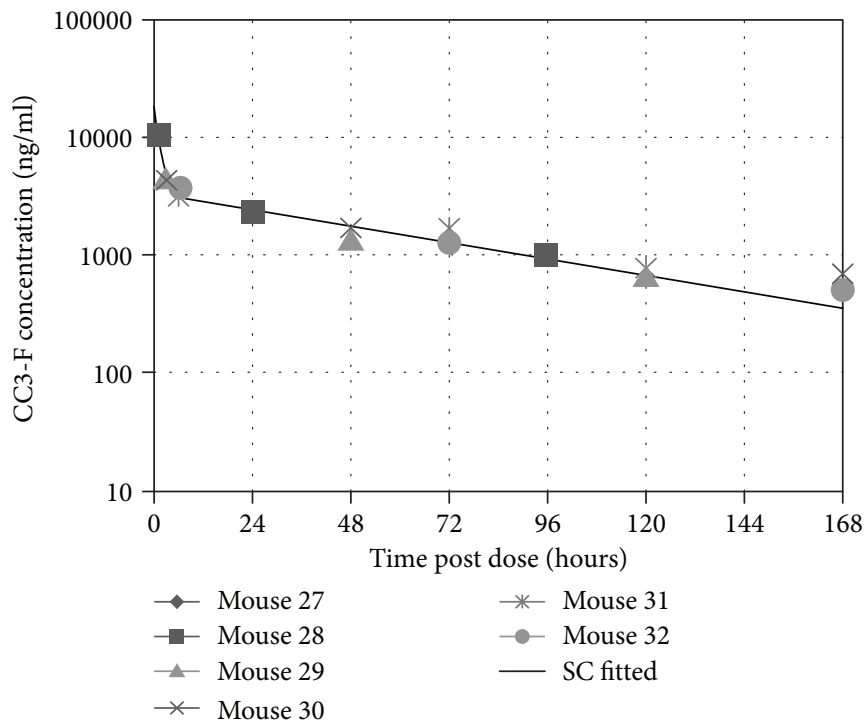

(b)

Figure 5: The PK profiles for an anti-mICOSL VNAR-Fc CC3-Fc dosed at $4 \mathrm{mg} / \mathrm{kg}$ i.v. and s.c. Composite profiles derived from 6 animals per route of administration: curve-fitted subcutaneously (a) and curve-fitted intravenously (b).

TABLE 1

\begin{tabular}{lcc}
\hline Parameter & Intravenous dose & Subcutaneous dose \\
\hline Clearance $(\mathrm{ml} / \mathrm{h} / \mathrm{kg})$ & 17.1 & 28.1 \\
Half-life $(\mathrm{h})$ & 52 & 38 \\
AUC $\left(\mathrm{h}^{*} \mu \mathrm{g} / \mathrm{ml}\right)$ & 234 & 142 \\
Bioavailability & & $61 \%$ \\
\hline
\end{tabular}

a potent anti-inflammatory corticosteroid, presented with no apparent disease pathology (vi) compared to the vehicle control (vii) which exhibited extensive cartilage destruction, bone erosion, pannus formation, and granulocyte infiltration (Figure 6(d)). These hallmarks of arthritis were also evident in both isotype control groups (iii and v) whereas A1- (i) and CC3- (ii) treated animals show greatly reduced joint damage similar to the levels seen in HK5.3treated samples (iv). Based on the histopathology sections, an analysis of the ankle RA scores from the left hind joint from each animal was conducted by measuring the level of inflammation, pannus formation, cartilage damage, bone resorption, and periosteal change. Each of these parameters was allocated a score from 1 to 5 and the summarised histopathology scores plotted in Figure 6(c).

\section{Discussion}

According to the latest population studies of people aged 18 to 64 , about one in three (both men and women) will have 


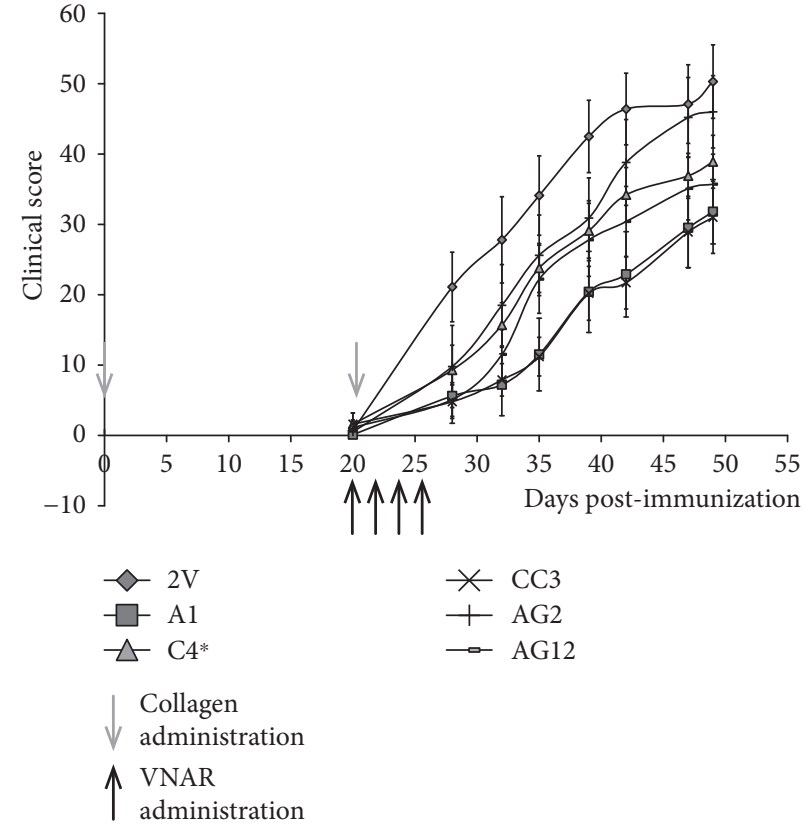

(a)

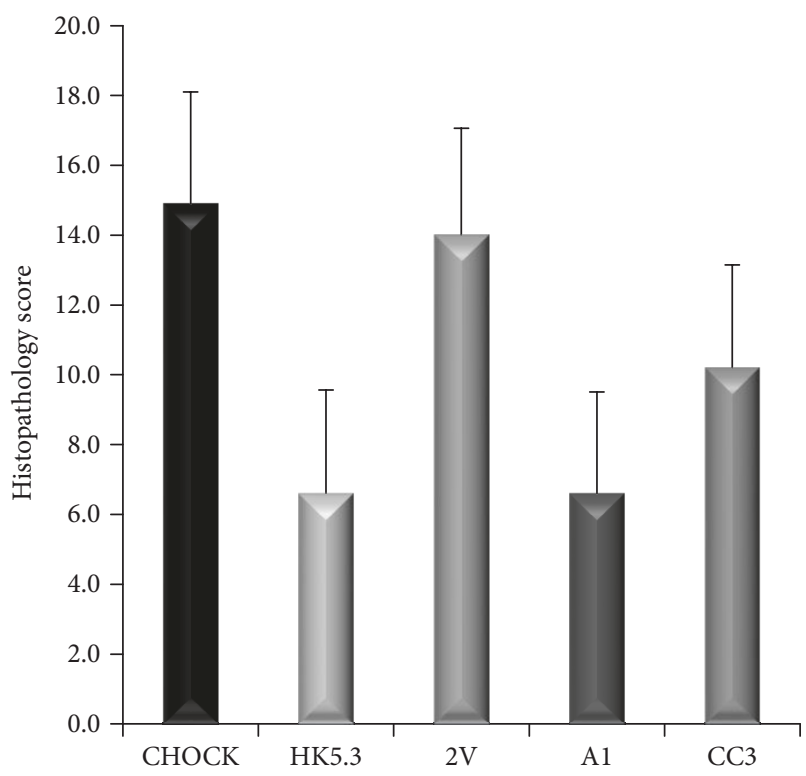

(c)

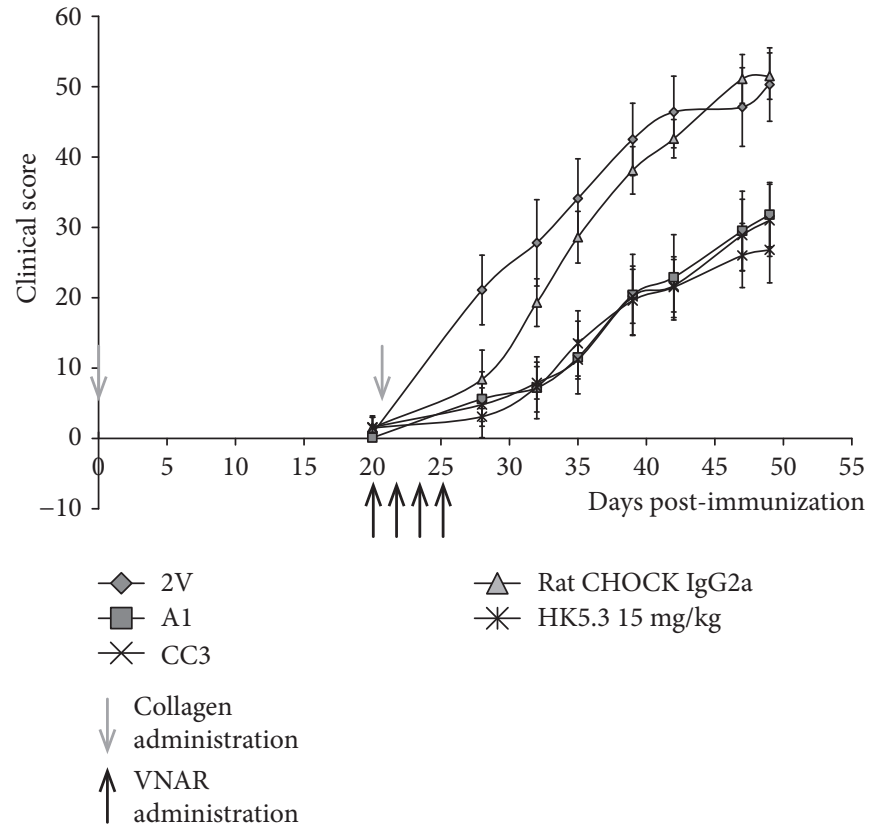

(b)
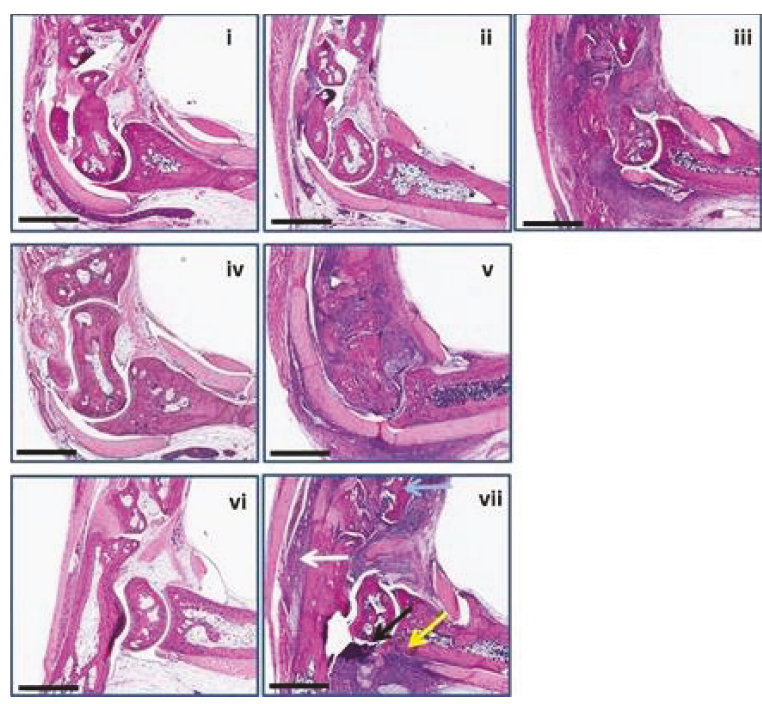

(d)

FIgure 6: Clinical scores and histopathology sections from the CIA study CIA study results. (a, b) Average clinical scores for each experimental group of 10 animals measured twice weekly for the duration of study. A collagen boost was given at day 20 and dosing of test samples at $15 \mathrm{mg} / \mathrm{kg}$ at days $19,21,23$, and 25. Data shown as an average clinical score \pm SEM and comparisons were made using the Mann-Whitney test. (c) Analysis of the ankle RA scores from the left hind joint from each animal: the level of inflammation, pannus formation, cartilage damage, bone resorption, and periosteal change was measured, and each of these parameters was allocated a score from 1 to 5 . The summarised histopathology scores were plotted. (d) Left hind paws from each experimental animal were sectioned and stained with H\&E. (i) A1-Fc, (ii) CC3-Fc, (iii) 2V-Fc, (iv) HK5.3, (v) IgG2a, (vi) dexamethasone, and (vii) vehicle control. Black arrow: an example region of bone erosion; grey arrow: an example region of bone resorption; white arrow: cellular infiltrate; yellow arrow: pannus formation. The size bar represents $2 \mathrm{~mm}$.

doctor-diagnosed arthritis and/or report joint symptoms consistent with a diagnosis of arthritis [52]. In the last decade, our knowledge of the underlying pathobiology of rheumatoid arthritis has significantly increased with targeted biological therapies providing clear evidence that multiple immunological and inflammatory pathways operate. Each year, new roles for cytokines, mediators, and pathways that show additional promise in unravelling the full complexity of the pathways driving RA disease are published [53-55]. ICOSL induces important costimulatory signals delivered 
through ICOS receptor molecules on the surface of the T cell, resulting in $\mathrm{T}$ cell activation. Therefore, it follows that interruption or blocking of this costimulatory signal pathway may provide a potential biological target and therapy option to treat RA.

Anti-ICOSL VNARs, derived from a synthetic Squalus acanthias library, were ranked based on their ability to inhibit the ICOS-ICOSL interaction. Five lead candidates were selected, and two of them showed comparable efficacy in a murine CIA model resulting in delayed onset of disease and reduced overall disease burden.

An important step in the development of biologics is the study of preclinical efficacy usually using rodent models. In some cases, a candidate molecule recognises and neutralises both the human and the orthologous protein in rat or mouse. For some targets, however, low species homology precludes the use of the same candidates in rodent models of preclinical efficacy with a second panel of rodent-specific binders used as surrogates to predict efficacy in a human setting [56-60]. We have tried previously and unfortunately failed to select neutralising species cross-reactive anti-ICOSL VNAR derived from an immunised shark library. Here, using a synthetic VNAR library, the introduction of cross-reactivity and blocking assays into the screening regime again generated VNAR domains capable of binding to both human and murine targets, but lacking the ability to block ICOS/ICOSL in both species. Therefore, the in vivo activity of anti-mICOSL-specific VNAR domains must again be considered as surrogates for the use of anti-hICOSL VNARs in patient therapy. It is also worth noting that in $\mathrm{T}$ cell proliferation assays, the selected anti-hICOSL VNAR domains demonstrate $100 x$ higher levels of potency $\left(\mathrm{EC}_{50}\right)$ than lead antimICOSL domains do, reinforcing the expectation that they would show excellent in vivo efficacy.

In the mouse CIA model HK5.3, a control rat anti-mouse ICOSL mAb, known to inhibit both Th1 and Th2 immune responses and ameliorate inflammatory arthritis [51], was used. When compared to HK5.3, the reduction in clinical score with A1 and CC3 VNAR-Fc domains was equivalent and significantly better than the $2 \mathrm{~V}-\mathrm{Fc}$ isotype control. In histopathological analysis, A1 and CC3 VNAR-Fc reduced cartilage destruction, bone erosion, pannus formation, and granulocyte infiltration, to the same extent as HK5.3 (Figure 6(d)). CC3 was administrated at $\sim 50 \%$ lower dose but still had comparable efficacy.

The flexible reformatting of VNAR domains was exemplified by the addition of a human $\mathrm{Fc}$ region to facilitate an increase in serum half-life and avidity of binding. Preliminary, single-dose, pharmacokinetic/pharmacodynamic studies administrated intravenously or subcutaneously resulted in considerable bioavailability and serum half-life for both routes of administration (Figure 5). At only $80 \mathrm{kDa}$, VNARFc provides a valuable therapeutic format for systemic administration. A new VNAR structure known as a Quad$\mathrm{X}^{\mathrm{TM}}$ delivers an Fc fusion and quadravalency $(100 \mathrm{kDa})$ and has shown even greater potency $(10 \mathrm{x})$ than that of the equivalent bivalent FC format, for an anti-TNF $\alpha$ VNAR domain [61]. It would be interesting to determine if a Quad- $\mathrm{X}^{\mathrm{TM}}$ version of candidate anti-ICOSL domains would see a similar uplift in potency.

\section{Conclusion}

Anti-ICOSL VNAR domains selected from a synthetic library have been shown to block receptor/ligand interaction in vitro and in cell-based assays as well as to inhibit human $\mathrm{T}$ cell proliferation with $\mathrm{pM}$ potency. When this in vitro bioassay potency is combined with the use of anti-mICOSL VNAR-Fc in vivo as surrogate drugs for accelerated development, these biologics exhibit excellent efficacy in a predictive mouse model of CIA demonstrating their ease of reformatting, simplicity of production, and potential to bring relief to the $40 \%$ of patients that do not respond to first-line anti-TNF therapies in RA and other debilitating autoimmune diseases.

\section{Abbreviations}

ACR: American College of Rheumatology

APC: Antigen-presenting cells

CDR: Complementarity determining region

CIA: Collagen-induced arthritis

FW: $\quad$ Framework

GC: Germinal centre

HV: Hypervariable region

ICOSL: Induced costimulatory ligand

IgNAR: Immunoglobulin-like new antigen receptor

PEG: $\quad$ Polyethylene glycol

RA: Rheumatoid arthritis

SLE: Systemic lupus erythematosus

$\mathrm{T}_{\mathrm{FH}}$ : Follicular helper $\mathrm{T}$ cells

VNAR: Variable domain of shark new antigen receptor

\section{Data Availability}

All data used to support the findings of this study are unavailable due to the commercially sensitive nature of the research.

\section{Conflicts of Interest}

The authors, Kovaleva, Steven, and Barelle, are employed by Elasmogen Ltd, a company involved in the development of therapeutic VNAR domains.

\section{Authors' Contributions}

Ronan O'Dwyer and Marina Kovaleva contributed equally to this work.

\section{Acknowledgments}

The authors wish to thank Phil Brain for his expert input into the statistical analysis and Prof. Andy Porter for proofreading the manuscript. 


\section{References}

[1] J. S. Smolen, D. Aletaha, and I. B. McInnes, "Rheumatoid arthritis," The Lancet, vol. 388, no. 10055, pp. 2023-2038, 2016.

[2] R. N. Maini and M. Feldmann, "How does infliximab work in rheumatoid arthritis?," Arthritis Research \& Therapy, vol. 4, Supplement 2, p. S22, 2002.

[3] L. M. Bang and G. M. Keating, “Adalimumab," BioDrugs, vol. 18, no. 2, pp. 121-139, 2004.

[4] D. J. Shealy, A. Cai, K. Staquet et al., "Characterization of golimumab, a human monoclonal antibody specific for human tumor necrosis factor $\alpha$," $m A b s$, vol. 2, no. 4, pp. 428-439, 2014.

[5] T. Bourne, G. Fossati, and A. Nesbitt, “A PEGylated Fab' fragment against tumor necrosis factor for the treatment of Crohn disease: exploring a new mechanism of action," BioDrugs, vol. 22, no. 5, pp. 331-337, 2008.

[6] A. Nesbitt, G. Fossati, M. Bergin et al., "Mechanism of action of certolizumab pegol (CDP870): in vitro comparison with other anti-tumor necrosis factor $\alpha$ agents," Inflammatory Bowel Diseases, vol. 13, no. 11, pp. 1323-1332, 2007.

[7] E. D. Deeks, "Certolizumab pegol: a review of its use in the management of rheumatoid arthritis," Drugs, vol. 73, no. 1, pp. 75-97, 2013.

[8] M. A. V. Willrich, D. L. Murray, and M. R. Snyder, "Tumor necrosis factor inhibitors: clinical utility in autoimmune diseases," Translational Research, vol. 165, no. 2, pp. 270282, 2015.

[9] P. E. Lipsky, D. van der Heijde, E. W. St Clair et al., "Infliximab and methotrexate in the treatment of rheumatoid arthritis. Anti-Tumor Necrosis Factor Trial in Rheumatoid Arthritis with Concomitant Therapy Study Group," The New England Journal of Medicine, vol. 343, no. 22, pp. 1594-1602, 2000.

[10] M. E. Weinblatt, E. C. Keystone, D. E. Furst et al., “Adalimumab, a fully human anti-tumor necrosis factor alpha monoclonal antibody, for the treatment of rheumatoid arthritis in patients taking concomitant methotrexate: the ARMADA trial," Arthritis and Rheumatism, vol. 48, no. 1, pp. 35-45, 2003.

[11] M. E. Weinblatt, R. Fleischmann, T. W. J. Huizinga et al., "Efficacy and safety of certolizumab pegol in a broad population of patients with active rheumatoid arthritis: results from the REALISTIC phase IIIb study," Rheumatology, vol. 51, no. 12, pp. 2204-2214, 2012.

[12] R. van Vollenhoven, C. Carli, J. Bratt, and L. Klareskog, "Six year report of the STURE Registry for biologicals in rheumatology: satisfactory overall results but plenty of room for improvemnt," Arthritis and Rheumatism, vol. 52, Supplement 9, p. S135, 2005.

[13] P. Emery, E. Keystone, H. P. Tony et al., "IL-6 receptor inhibition with tocilizumab improves treatment outcomes in patients with rheumatoid arthritis refractory to anti-tumour necrosis factor biologicals: results from a 24 -week multicentre randomised placebo-controlled trial," Annals of the Rheumatic Diseases, vol. 67, no. 11, pp. 1516-1523, 2008.

[14] S. B. Cohen, P. Emery, M. W. Greenwald et al., "Rituximab for rheumatoid arthritis refractory to anti-tumor necrosis factor therapy: results of a multicenter, randomized, double-blind, placebo-controlled, phase III trial evaluating primary efficacy and safety at twenty-four weeks," Arthritis and Rheumatism, vol. 54, no. 9, pp. 2793-2806, 2006.
[15] M. C. Genovese, J. C. Becker, M. Schiff et al., “Abatacept for rheumatoid arthritis refractory to tumor necrosis factor $\alpha$ inhibition," The New England Journal of Medicine, vol. 353, no. 11, pp. 1114-1123, 2005.

[16] H. Dooley, M. F. Flajnik, and A. J. Porter, "Selection and characterization of naturally occurring single-domain (IgNAR) antibody fragments from immunized sharks by phage display," Molecular Immunology, vol. 40, no. 1, pp. 25-33, 2003.

[17] M. R. Müller, K. Saunders, C. Grace et al., "Improving the pharmacokinetic properties of biologics by fusion to an antiHSA shark VNAR domain," $m A b s$, vol. 4, no. 6, pp. 673-685, 2012.

[18] H. Dooley, R. L. Stanfield, R. A. Brady, and M. F. Flajnik, "First molecular and biochemical analysis of in vivo affinity maturation in an ectothermic vertebrate," Proceedings of the National Academy of Sciences of the United States of America, vol. 103, no. 6, pp. 1846-1851, 2006.

[19] A. S. Greenberg, D. Avila, M. Hughes, A. Hughes, E. Churchill McKinney, and M. F. Flajnik, "A new antigen receptor gene family that undergoes rearrangement and extensive somatic diversification in sharks," Nature, vol. 374, no. 6518, pp. 168-173, 1995.

[20] H. Dooley and M. F. Flajnik, "Antibody repertoire development in cartilaginous fish," Developmental and Comparative Immunology, vol. 30, no. 1-2, pp. 43-56, 2006.

[21] M. F. Criscitiello, "What the shark immune system can and cannot provide for the expanding design landscape of immunotherapy," Expert Opinion on Drug Discovery, vol. 9, no. 7, pp. 725-739, 2014.

[22] S. Zielonka, M. Empting, J. Grzeschik, D. Konning, C. J. Barelle, and H. Kolmar, "Structural insights and biomedical potential of IgNAR scaffolds from sharks," MAbs, vol. 7, no. 1, pp. 15-25, 2015.

[23] R. L. Stanfield, H. Dooley, M. F. Flajnik, and I. A. Wilson, "Crystal structure of a shark single-domain antibody V region in complex with lysozyme," Science, vol. 305, no. 5691, pp. 1770-1773, 2004.

[24] V. A. Streltsov, J. N. Varghese, J. A. Carmichael, R. A. Irving, P. J. Hudson, and S. D. Nuttall, "Structural evidence for evolution of shark Ig new antigen receptor variable domain antibodies from a cell-surface receptor," Proceedings of the National Academy of Sciences of the United States of America, vol. 101, no. 34, pp. 12444-12449, 2004.

[25] R. L. Stanfield, H. Dooley, P. Verdino, M. F. Flajnik, and I. A. Wilson, "Maturation of shark single-domain (IgNAR) antibodies: evidence for induced-fit binding," Journal of Molecular Biology, vol. 367, no. 2, pp. 358-372, 2007.

[26] C. Barelle, D. S. Gill, and K. Charlton, "Shark novel antigen receptors-the next generation of biologic therapeutics?," Advances in Experimental Medicine and Biology, vol. 655, pp. 49-62, 2009.

[27] K. Griffiths, O. Dolezal, K. Parisi et al., "Shark variable new antigen receptor (VNAR) single domain antibody fragments: stability and diagnostic applications," Antibodies, vol. 2, no. 4, pp. 66-81, 2013.

[28] J. L. Liu, D. Zabetakis, J. C. Brown, G. P. Anderson, and E. R. Goldman, "Thermal stability and refolding capability of shark derived single domain antibodies," Molecular Immunology, vol. 59, no. 2, pp. 194-199, 2014.

[29] M. Kovaleva, L. Ferguson, J. Steven, A. Porter, and C. Barelle, "Shark variable new antigen receptor biologics - a novel 
technology platform for therapeutic drug development," Expert Opinion on Biological Therapy, vol. 14, no. 10, pp. 1527-1539, 2014.

[30] M. Hegen, J. C. Keith, M. Collins, and C. L. NickersonNutter, "Utility of animal models for identification of potential therapeutics for rheumatoid arthritis," Annals of the Rheumatic Diseases, vol. 67, no. 11, pp. 1505-1515, 2008.

[31] M. M. Swallow, J. J. Wallin, and W. C. Sha, "B7h, a novel costimulatory homolog of B7.1 and B7.2, is induced by TNF $\alpha$," Immunity, vol. 11, no. 4, pp. 423-432, 1999.

[32] S. K. Yoshinaga, J. S. Whoriskey, S. D. Khare et al., "T-cell costimulation through B7RP-1 and ICOS," Nature, vol. 402, no. 6763 , pp. $827-832,1999$.

[33] H. W. Mages, A. Hutloff, C. Heuck et al., "Molecular cloning and characterization of murine ICOS and identification of B7h as ICOS ligand," European Journal of Immunology, vol. 30, no. 4, pp. 1040-1047, 2000.

[34] A. Hutloff, A. M. Dittrich, K. C. Beier et al., "ICOS is an inducible T-cell co-stimulator structurally and functionally related to CD28," Nature, vol. 397, no. 6716, pp. 263-266, 1999.

[35] S. K. Yoshinaga, M. Zhang, J. Pistillo et al., "Characterization of a new human B7-related protein: B7RP-1 is the ligand to the co-stimulatory protein ICOS," International Immunology, vol. 12, no. 10, pp. 1439-1447, 2000.

[36] A. Aicher, M. Hayden-Ledbetter, W. A. Brady et al., "Characterization of human inducible costimulator ligand expression and function," Journal of Immunology, vol. 164, no. 9, pp. 4689-4696, 2000.

[37] H. Akiba, K. Takeda, Y. Kojima et al., "The role of ICOS in the CXCR5+ follicular B helper T cell maintenance in vivo," Journal of Immunology, vol. 175, no. 4, pp. 2340-2348, 2005.

[38] Y. Burmeister, T. Lischke, A. C. Dahler et al., "ICOS controls the pool size of effector-memory and regulatory $\mathrm{T}$ cells," Journal of Immunology, vol. 180, no. 2, pp. 774782,2008

[39] D. Liu, H. Xu, C. Shih et al., "T-B-cell entanglement and ICOSL-driven feed-forward regulation of germinal centre reaction," Nature, vol. 517, no. 7533, pp. 214-218, 2015.

[40] B. A. Sullivan, W. Tsuji, A. Kivitz et al., "Inducible T-cell co-stimulator ligand (ICOSL) blockade leads to selective inhibition of anti-KLH IgG responses in subjects with systemic lupus erythematosus," Lupus Science \& Medicine, vol. 3, no. 1, article e000146, 2016.

[41] L. E. Cheng, Z. Amoura, B. Cheah et al., "Brief report: a randomized, double-blind, parallel-group, placebo-controlled, multiple-dose study to evaluate AMG 557 in patients with systemic lupus erythematosus and active lupus arthritis," Arthritis \& Rheumatology, vol. 70, no. 7, pp. 1071-1076, 2018.

[42] M. Kovaleva, K. Johnson, J. Steven, C. J. Barelle, and A. Porter, "Therapeutic potential of shark anti-ICOSL VNAR domains is exemplified in a murine model of autoimmune non-infectious uveitis," Frontiers in Immunology, vol. 8, p. 1121, 2017.

[43] K. Larimore, L. Liang, S. Bakkour, and W. C. Sha, "B7hexpressing dendritic cells and plasma B cells mediate distinct outcomes of ICOS costimulation in T cell-dependent antibody responses," BMC Immunology, vol. 13, no. 1, p. 29, 2012.

[44] O. Frey, J. Meisel, A. Hutloff et al., "Inducible costimulator (ICOS) blockade inhibits accumulation of polyfunctional T helper 1/T helper 17 cells and mitigates autoimmune arthritis,"
Annals of the Rheumatic Diseases, vol. 69, no. 8, pp. 14951501,2010

[45] Y. Usui, H. Akiba, M. Takeuchi et al., "The role of the ICOS/ B7RP-1 T cell costimulatory pathway in murine experimental autoimmune uveoretinitis," European Journal of Immunology, vol. 36, no. 11, pp. 3071-3081, 2006.

[46] Y. L. Hu, D. P. Metz, J. Chung, G. Siu, and M. Zhang, "B7RP-1 blockade ameliorates autoimmunity through regulation of follicular helper T cells," Journal of Immunology, vol. 182, no. 3, pp. 1421-1428, 2009.

[47] K. M. Hamel, Y. Cao, S. A. Olalekan, and A. Finnegan, "B cell-specific expression of inducible costimulator ligand is necessary for the induction of arthritis in mice," Arthritis \& Rheumatology, vol. 66, no. 1, pp. 60-67, 2014.

[48] K. M. Hamel, Y. Cao, S. A. Olalekan, and A. Finnegan, "B cell-specific expression of inducible costimulator ligand is necessary for the induction of arthritis in mice," Arthritis and Rheumatism, vol. 66, no. 1, pp. 60-67, 2014.

[49] M. R. Müller, R. O’Dwyer, M. Kovaleva, F. Rudkin, H. Dooley, and C. J. Barelle, "Generation and isolation of target-specific single-domain antibodies from shark immune repertoires," Methods in Molecular Biology, vol. 907, pp. 177-194, 2012.

[50] J. Steven, M. R. Müller, M. F. Carvalho et al., "In vitro maturation of a humanized shark Vnar domain to improve its biophysical properties to facilitate clinical development," Frontiers in Immunology, vol. 8, p. 8, 2017.

[51] H. Iwai, Y. Kozono, S. Hirose et al., "Amelioration of collageninduced arthritis by blockade of inducible costimulator-B7 homologous protein costimulation," Journal of Immunology, vol. 169, no. 8, pp. 4332-4339, 2002.

[52] S. R. Jafarzadeh and D. T. Felson, "Updated estimates suggest a much higher prevalence of arthritis in united states adults than previous ones," Arthritis \& Rheumatology, vol. 70, no. 2, pp. 185-192, 2018.

[53] E. Choy, "Understanding the dynamics: pathways involved in the pathogenesis of rheumatoid arthritis," Rheumatology, vol. 51, Supplement 5, pp. v3-v11, 2012.

[54] S. Nalbant and A. M. Birlik, "Cytokines in rheumatoid arthritis (RA)," in New Developments in the Pathogenesis of Rheumatoid Arthritis, L. I. Sakkas, Ed., IntechOpen, Rijeka, Croatia, 2017.

[55] F. Ferro, E. Elefante, N. Luciano, R. Talarico, and M. Todoerti, "One year in review 2017: novelties in the treatment of rheumatoid arthritis," Clinical and Experimental Rheumatology, vol. 35, no. 5, pp. 721-734, 2017.

[56] G. Treacy, "Using an analogous monoclonal antibody to evaluate the reproductive and chronic toxicity potential for a humanized anti-TNFa monoclonal antibody," Human \& Experimental Toxicology, vol. 19, no. 4, pp. 226-228, 2000.

[57] B. Wu, A. Joshi, S. Ren, and C. Ng, "The application of mechanism-based PK/PD modeling in pharmacodynamicbased dose selection of muM17, a surrogate monoclonal antibody for efalizumab," Journal of Pharmaceutical Sciences, vol. 95, no. 6, pp. 1258-1268, 2006.

[58] J. Uchida, Y. Hamaguchi, J. A. Oliver et al., "The innate mononuclear phagocyte network depletes B lymphocytes through $\mathrm{Fc}$ receptor-dependent mechanisms during antiCD20 antibody immunotherapy," The Journal of Experimental Medicine, vol. 199, no. 12, pp. 1659-1669, 2004.

[59] G. Garrido, B. Sanchez, H. M. Rodriguez, P. Lorenzano, D. Alonso, and L. E. Fernandez, "7A7 MAb: a new tool for 
the pre-clinical evaluation of EGFR-based therapies," Hybridoma and Hybridomics, vol. 23, no. 3, pp. 168-175, 2004.

[60] J. Clarke, W. Leach, S. Pippig et al., "Evaluation of a surrogate antibody for preclinical safety testing of an anti-CD11a monoclonal antibody," Regulatory Toxicology and Pharmacology, vol. 40, no. 3, pp. 219-226, 2004.

[61] O. C. Ubah, J. Steven, M. Kovaleva et al., "Novel, anti-hTNF- $\alpha$ variable new antigen receptor formats with enhanced neutralizing potency and multifunctionality, generated for therapeutic development," Frontiers in Immunology, vol. 8, 2017. 


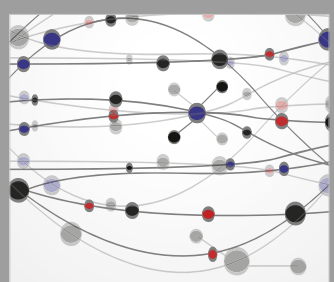

The Scientific World Journal
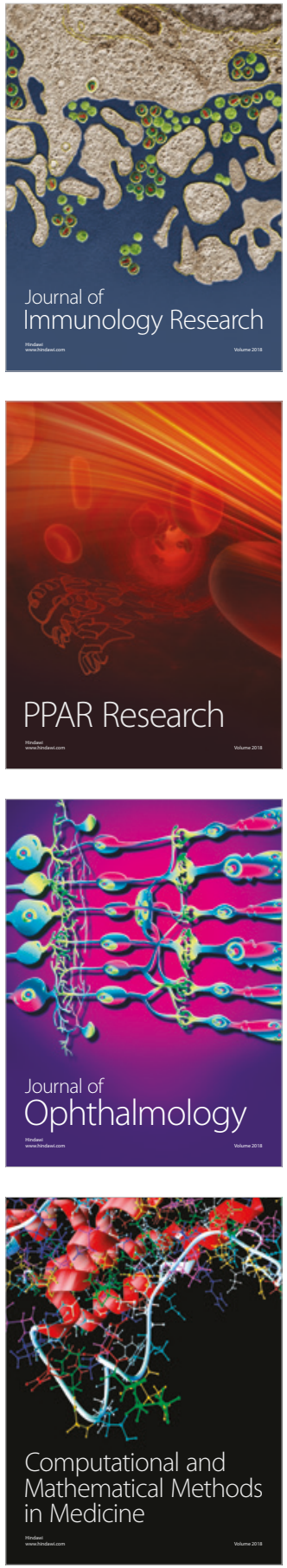

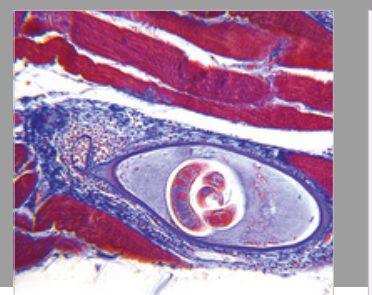

Gastroenterology Research and Practice

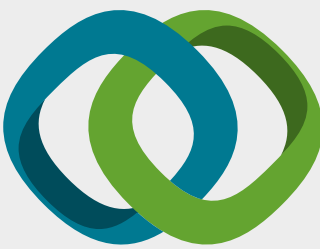

\section{Hindawi}

Submit your manuscripts at

www.hindawi.com
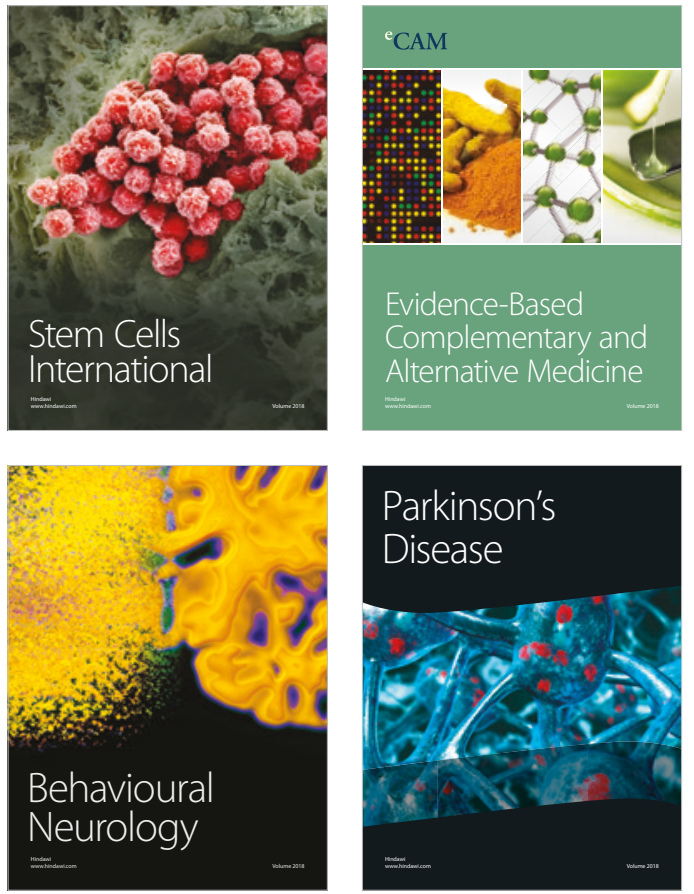

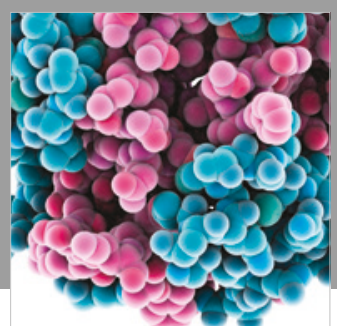

ournal of

Diabetes Research

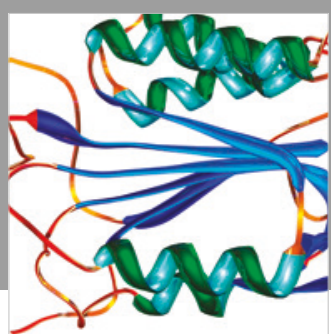

Disease Markers
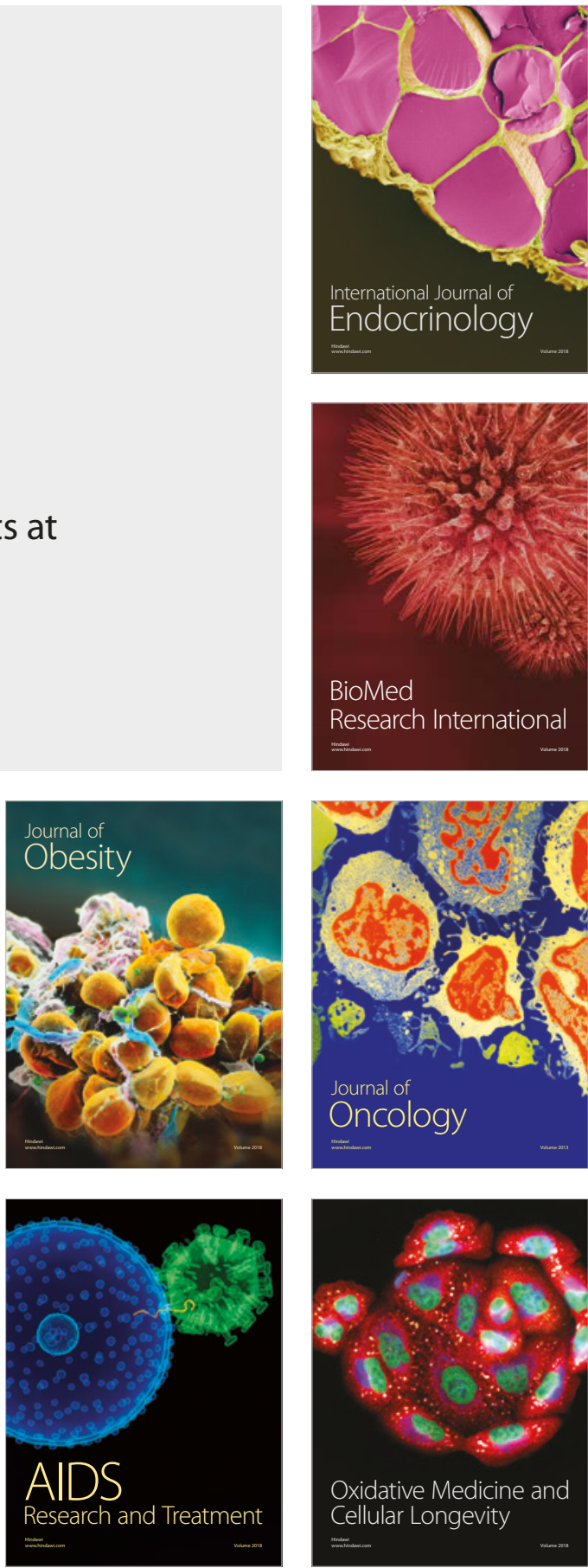